\title{
Laboratory Measurements of Air Cavity Temperature in a Passenger Car Tire
}

\author{
B. G. Simson and J. Mandel \\ Institute for Applied Technology, National Bureau of Standards, Washington, D.C. 20234 \\ (May 7, 1969)

\begin{abstract}
The air cavity temperature of a passenger car tire, running on a test wheel, was measured for different combinations of load, speed, and pressure. An empirical function was developed to illustrate the way in which the air cavity temperature of tires can be related adequately to given values of speed, load, and inflation pressure within the range covered by this laboratory experiment. The standard deviation computed from the residuals of the fit was $5^{\circ} \mathrm{F}\left(\simeq 2.8^{\circ} \mathrm{C}\right)$.
\end{abstract}

Key words: Temperature sensitivity; tires.

\section{Introduction}

Excessive heat causes tire failure. Therefore, it is important to measure temperature buildup in different parts of a running tire and in the air cavity of the tire. Several investigators have reported on such experiments performed on passenger car and truck tires $[1,2,3,4]$. $^{1}$ D. M. Coddington et al. [1], developed response functions for tire temperature in road tests. Our work was carried out on an endurance wheel under controlled laboratory conditions. The study was conducted to determine whether the air cavity temperature of a typical passenger car tire could be fitted by a simple empirical function of speed, load, and inflation pressure.

\section{Equipment and Procedure}

The test wheel as well as the experimental tire testing procedure were in accordance with MVSS-109 [5]. Figure 1 shows a schematic of the experimental setup for measuring air cavity temperature. A thermistor, potted into the tip of a steel tube, is inserted into the air cavity to a depth of six-tenths of the crosssectional tire height. Preliminary experiments showed that at this depth temperature measurements were relatively stable. A Wheatstone bridge, connected to the probe through slip rings, served as a readout device. An oil bath on a hot plate was used to calibrate the probe and the bridge against a mercury thermometer.

Temperature measurements were taken near the end of each one-hour test period. The independent variables and their levels were as follows:

${ }^{1}$ Figures in brackets indicate the literature references at the end of this paper.
Speed: $\quad 30,40,50,60,70 \mathrm{mph}(13.41,17.88,22.35$, $26.82,31.29 \mathrm{~m} / \mathrm{s}$ )

Load: $\quad 928,1044,1160,1276,1392,1508,1624 \mathrm{lbs}$ $(4.13,4.64,5.16,5.68,6.19,6.71,7.29 \mathrm{kN})$

Pressure: 24, 26, 28, 32 psi $(165.47,179.26,193.05$, $220.63 \mathrm{kN} / \mathrm{m}^{2}$ ).

All combinations were run. From the viewpoint of expedient laboratory procedure, a sequence of tests in

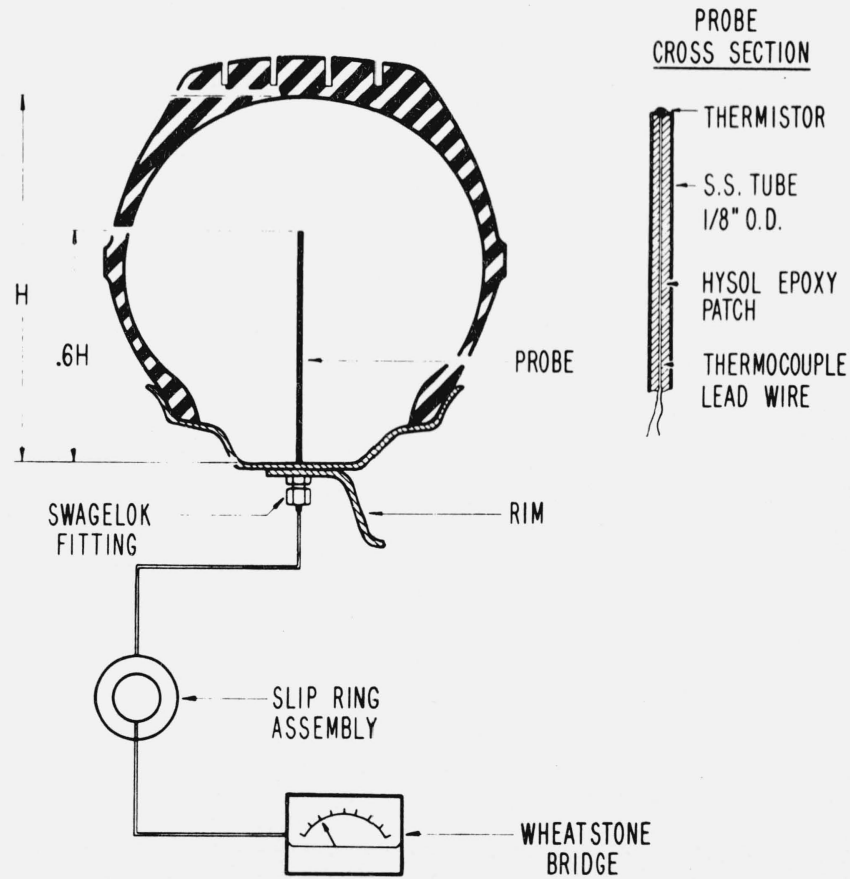

FIGURE 1. Monitoring of tire air cavity temperature. 
which all variables are allowed to change between consecutive measurements is impractical: Any change in pressure requires a shut down of the equipment for at least three hours to allow the tire to come to equilibrium with the environmental temperature. On the other hand, speed and load can be varied readily without interrupting the test. For these reasons, the experiment was run in four parts, ${ }^{2}$ corresponding to the four pressure levels, taken in random order. Within each part, the sequence of tests corresponding to the various speed and load combinations was randomized. To increase the validity of the experiment, it was decided to use four nominally identical tires: 7.35-14, 4-ply nylon from a single manufacturer. This design involves a confounding of the effect of pressure with the variability between nominally identical tires. On the other hand, the four-fold replication of all speed-load combinations, using four separate tires, reduces the uncertainty of the results with respect to the effects of speed and load. The results found in this investigation will therefore have greater precision with respect to the effects of speed and load than with regard to the effect of pressure. All pressures were measured with the same commercial gage to within $1 / 2$ psi at the beginning of each run after the tire load reached environmental temperature, and the equipment was kept under controlled environmental conditions throughout the entire experiment.

${ }^{2}$ Originally the plan included five pressure levels: $24,26,28,30$, and 32 psi. However, an equipment break down prevented testing at the $30 \mathrm{psi}$ level.

\section{Statistical Analysis}

Prior to an analysis of variance of the data, an estimate was obtained for the missing value in table $1(a)$. This estimate was computed by fitting a straight line to the values in the last row of this table versus the column averages of the remaining rows, and taking the value fitted at the point corresponding to $70 \mathrm{mph}$. In the subsequent analysis, the value thus computed was considered as a genuine measurement.

Table 2 shows result of an analysis of variance of the data. The interactions $P \times S$ and $L \times S$ are not significant at the 5 percent level. This means that the effects of pressure and load can be considered not to depend on the level of speed at which they are determined. Another way of stating this result is that the curves representing the relationship between temperature and pressure at various levels of speed are essentially parallel to each other, with a similar situation holding for the curves relating temperature to load. Pooling these nonsignificant terms with the three factor interactions yields a mean square of 20.49 , as shown in the table. The remaining two factor interaction $(P \times L)$ is not significant with respect to this pooled value. Thus, the effect of pressure is also essentially the same at all levels of load. It may be concluded that the data are adequately expressed by an additive model. To determine the effects of speed, load, and pressure on temperature by the method of least squares, it is, therefore, sufficient to consider the marginal averages of the three-way array composed of tables $1(a), 1(b), 1(c)$, and $1(d)$. Plots of these rela-

TABLE 1. Air cavity temperature of a tire in ${ }^{\circ} F^{*}$ for different combinations of load and speed

A different pressure level is used for part $1(a), 1(b), 1(c)$, and $1(d)$, respectively.

\begin{tabular}{|c|c|c|c|c|c|c|c|c|c|c|c|}
\hline \multicolumn{6}{|c|}{ Part 1(a): Pressure $=24$ psi } & \multicolumn{6}{|c|}{ Part l(b): Pressure $=26$ osi } \\
\hline \multirow{2}{*}{$\begin{array}{l}\text { LOAD } \\
\text { (LBS) }\end{array}$} & \multirow[b]{2}{*}{30} & \multicolumn{4}{|c|}{ SPEED (MPH) } & \multirow{2}{*}{$\begin{array}{l}\text { LOAD } \\
\text { (LBS) }\end{array}$} & & \multicolumn{4}{|c|}{ SPEED (MPH) } \\
\hline & & 40 & 50 & 60 & 70 & & 30 & 40 & 50 & 60 & 70 \\
\hline 928 & 141 & 151 & 160 & 168 & 180 & 928 & 140 & 150 & 157 & 170 & 174 \\
\hline 1,044 & 145 & 167 & 167 & 177 & 193 & 1,044 & 145 & 155 & 170 & 175 & 190 \\
\hline 1,160 & 150 & 162 & 177 & 186 & 206 & 1,160 & 150 & 165 & 174 & 185 & 200 \\
\hline 1,276 & 157 & 172 & 192 & 204 & 215 & 1,276 & 152 & 175 & 185 & 195 & 205 \\
\hline 1,392 & 165 & 186 & 201 & 212 & 222 & 1,392 & 170 & 175 & 190 & 200 & 215 \\
\hline 1,508 & 181 & 192 & 212 & 226 & 232 & 1,508 & 172 & 187 & 200 & 210 & 230 \\
\hline \multirow[t]{3}{*}{1,624} & 184 & 205 & 222 & 232 & - \# & 1,624 & 174 & 190 & 205 & 220 & 230 \\
\hline & & 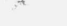 & & & & & & & & & \\
\hline & \multicolumn{5}{|c|}{ Part 1(c): Pressure $=28$ psi } & \multicolumn{6}{|c|}{ Part 1(d): Pressure $=32$ psi } \\
\hline \multirow{2}{*}{$\begin{array}{l}\text { LOAD } \\
\text { (LBS) }\end{array}$} & \multirow[b]{2}{*}{30} & \multirow{2}{*}{\multicolumn{3}{|c|}{$\begin{array}{cr}\text { SPEED } & (\mathrm{MPH}) \\
50 & 60\end{array}$}} & \multirow[b]{2}{*}{70} & \multirow{2}{*}{$\begin{array}{l}\text { LOAD } \\
\text { (LBS) }\end{array}$} & \multirow[b]{2}{*}{30} & \multirow{2}{*}{\multicolumn{3}{|c|}{$\begin{array}{cr}\text { SPEED } & \text { (MPH) } \\
50 & 60\end{array}$}} & \\
\hline & & & & & & & & & & & 70 \\
\hline 928 & 130 & 134 & 150 & 157 & 170 & 928 & 131 & 143 & 150 & 159 & 166 \\
\hline 1,044 & 130 & 150 & 152 & 172 & 175 & 1,044 & 133 & 148 & 158 & 162 & 179 \\
\hline 1,160 & 149 & 156 & 171 & 185 & 192 & 1,160 & 138 & 154 & 159 & 171 & 186 \\
\hline 1,276 & 158 & 161 & 183 & 189 & 205 & 1,276 & 151 & 165 & 169 & 183 & 191 \\
\hline 1,392 & 172 & 170 & 182 & 201 & 208 & 1,392 & 154 & 155 & 180 & 194 & 205 \\
\hline 1,508 & 173 & 174 & 200 & 199 & 202 & 1,508 & 166 & 177 & 191 & 200 & 207 \\
\hline 1,624 & 174 & 195 & 213 & 218 & 225 & 1,624 & 174 & 185 & 196 & 208 & 219 \\
\hline
\end{tabular}

*To convert to ${ }^{\circ} \mathrm{C}$, use the formula: $t_{c}=\frac{\left(t_{f}-32\right)}{1.8}$

\# No experimental value obtained because of equipment breakdown. A calculated value of 242 was inserted in this cell for the purpose of the statistical analysis (see text). 
TABLE 2. Analysis of variance of tire air cavity temperature

\begin{tabular}{|c|c|c|c|}
\hline Source of variation & $\begin{array}{c}\text { Degree of } \\
\text { freedom }\end{array}$ & $\begin{array}{l}\text { Sum of } \\
\text { squares }\end{array}$ & Mean square \\
\hline Total.. & 139 & 87845.13 & \\
\hline Pressure...... & 3 & 5365.74 & 1788.58 \\
\hline Load........ & 6 & 41281.47 & 6880.25 \\
\hline Speed...... & 4 & 38236.95 & 9559.24 \\
\hline $\begin{array}{l}\text { Pressure } \times \text { Load } \\
\quad(P \times L) \ldots \ldots \ldots \ldots .\end{array}$ & 18 & 747.95 & 4l. 55 \\
\hline $\begin{array}{l}\text { Pressure } \times \text { Speed } \\
\quad(P \times S)\end{array}$ & 12 & 335.33 & 27.94! \\
\hline Load $\times$ Speed $(L \times S)$ & $24\} 108$ & 756.24 & $31.51\} 20.49 *$ \\
\hline Error....................... & 72 & 1121.45 & 15.58 \\
\hline
\end{tabular}

*Pooled variance.

tionships are shown in figure 2. While the relations between temperature and speed and between temperature and load are adequately represented by straight lines, the dependence of temperature on pressure shows noticeable curvature. Straight lines were fitted to the first two sets and a quadratic to the third sel.


FIGURE 2. Marginal averages of temperature versus speed, load, and pressure.
The final results are given by the following equation:

$$
T=235.8+1.168 S+0.0738 L-13.035 P+0.1954 P^{2}
$$

where $T=$ air cavity temperature $\left({ }^{\circ} \mathrm{F}\right), S=$ speed (MPH), $L=$ load (lbs), and $P=$ pressure (psi).

Figure 3 shows the computed and observed tire cavity temperature for a number of combinations of speed, load, and pressure. The standard deviation computed from the residuals of the fit was $5{ }^{\circ} \mathrm{F}$ $\left(\simeq 2.8^{\circ} \mathrm{C}\right)$.

\section{- CALCULATED TeMPERATURE \\ - - OBSERVED TEMPERATURE}
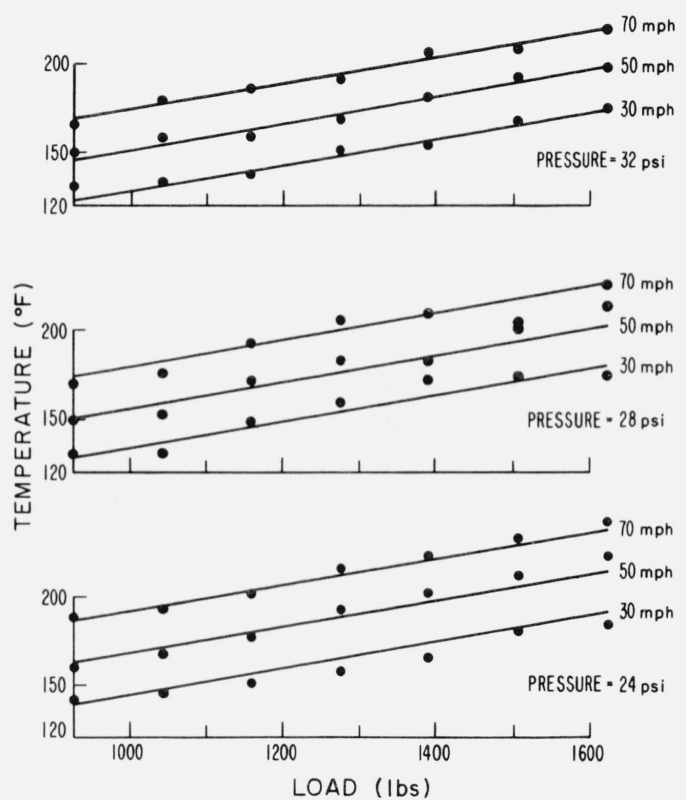

Figure 3. Computed and observed tire cavity temperature for several combinations of speed, load, and pressure.

\section{Conclusion}

An empirical temperature function for the air cavity temperature of a running tire was developed. Within given ranges of speed, load, and pressure this function adequately fits the air cavity temperature data for a particular passenger tire. It remains to be seen whether an equation of the above type is a valid expression for temperature dependence on speed, load, and pressure for other types of tires.

The authors are indebted to Robert Pizer for his assistance in instrumentation design, and to Glenn Ludwig and Dallas Rhodes for implementation of the experiment and collection of the data.

\section{References}

[1] Coddington, D. M., Marsh, W. D., and Hodges, H. C., New approach to tire durability testing, Rubber Chem. \& Tech. 38, No. 4, 741 (1965). 
[2] Richey, G. G., Hobbs, R. H., and Stiehler, R. D., Temperature studies of the air in a truck tire, Rubber Age 79, 273 (1956).

[3] "Tire Testing," a presentation by the Industrial Products Research Division of duPont, Wilmington, Del., on May 9, 1967, at NBS.
[4] Stiehler, R. D., Steel, M. N., Richey, G. G., Mandel, J., and Hobbs, R. H., Power loss and operating temperatures of tires, J. Res. NBS 64C (Eng. and Instr.) No. 1, 1 (1960).

[5] Motor Vehicle Safety Standard No. 109, New pneumatic tirespassenger cars, 32 F. R. 15792 (November 16, 1967).

(Paper 73C1 \& 2-287) 